\title{
Consumo e digestibilidade total dos nutrientes e produção e composição do leite de vacas alimentadas com teores crescentes de proteína bruta na dieta contendo cana-de-açúcar e concentados ${ }^{1}$
}

\author{
Carla Fabrícia de Araujo Cordeiro², Mara Lúcia Albuquerque Pereira ${ }^{3}$, Sandro de Souza \\ Mendonça ${ }^{4}$, Paulo José Presidio Almeida ${ }^{5}$, Luzyanne Varjão Aguiar ${ }^{6}$, Mauro Pereira de
} Figueiredo $^{7}$

\footnotetext{
1 Parte da Dissertação de Mestrado apresentada pela primeira autora à UESB.

${ }^{2}$ Mestre em Zootecnia (Produção de Ruminantes) pela UESB.

${ }^{3}$ DEBI/UESB.

${ }^{4}$ Doutorando pela UNESP/Jaboticabal.

${ }^{5}$ Graduando e bolsista de Iniciação Científica da FAPESB

${ }^{6}$ Graduando e bolsista de Apoio Técnico da FAPESB.

7 DFZ/UESB.
}

RESUMO - Objetivou-se avaliar o efeito de teores crescentes de PB na MS total da dieta (11,5; 13,0; 14,5 e 16,0\%) sobre os consumos e a digestibilidade total dos nutrientes e a produção e composição do leite de vacas leiteiras no terço inicial da lactação. O experimento foi constituído de quatro períodos experimentais de 15 dias, sete para adaptação dos animais à dieta e oito para coleta de dados. Foram utilizadas oito vacas, manejadas em cochos individuais, distribuídas em dois quadrados latinos balanceados $4 \times 4$. Utilizou-se concentrado à base de farelo de algodão e fubá de milho (40\%) e, como volumoso, cana-de-açúcar corrigida com $1 \%$ de uréia + sulfato de amônio (9:1), na proporção de $60 \%$ (\% MS). Os consumos médios diários de nutrientes, exceto EE e CNF, diferiram à medida que os teores de $\mathrm{PB}$ da dieta aumentaram. Os teores de PB na dieta não afetaram os coeficientes de digestibilidade aparente total dos nutrientes. A produção de leite corrigida ou não para 3,5\% de gordura e seus componentes (gordura, PB e lactose), expressa em g/dia, e o nitrogênio uréico no leite (NUL) tiveram efeito linear crescente, enquanto a eficiência de utilização de $\mathrm{N}$ sofreu efeito linear negativo dos teores de PB da dieta. A dieta com 16\% PB resultou em valores numericamente maiores de consumo e produção do leite e de seus componentes se comparada às dietas com menores teores de PB.

Palavras-chave: farelo de algodão, proteína não-degradável no rúmen, terço inicial da lactação

\section{Intake and total digestibility of nutrients and milk production and composition in dairy cows fed with increasing crude protein levels in the diet with sugar cane and concentrates}

ABSTRACT - The objective of this research was to evaluate the effect of increasing levels of CP in the total DM of diet $(11.5,13.0,14.5$ and $16.0 \%)$ on the intakes and the total digestibility of nutrients and the milk production and composition of dairy cows in initial third of lactation. The research was constituted by four experimental periods of 15 days each, seven for adaptation of the animals to the diet and eight for data collection. Eight cows, individually fed, were distributed to two balanced $4 \times 4$ Latin squares. A cottonseed meal, ground corn-based concentrate ( $40 \%)$ was used and, as forage, sugar cane corrected with $1 \%$ of urea + ammonium sulfate (9:1), in the proportion of $60 \%$ (\%DM). The daily average intakes of nutrients, except for EE and NFC, differed as the levels of CP increased in the diet. The protein levels in the diet did not affected the coefficients of total apparent digestibility of the nutrients. Production of fat corrected milk, 3.5\% or not and its components (fat, CP and lactose), expressed in g/day, and milk urea nitrogen showed increased linear effect, while the $\mathrm{N}$ efficiency showed negative linear effect of the CP levels in the diet. The diet with $16 \% \mathrm{CP}$ provided values numerically greater for intake and milk production and its components as compared to diets with lower levels of CP.

Key Words: cottonseed meal, early lactation, rumen undegradable protein 


\section{Introdução}

No início da lactação, as exigências nutricionais podem não ser completamente supridas, em razão da quantidade de leite produzida, pois ocorre redução na taxa de ingestão, resultando em balanço energético negativo, que limita a capacidade de suprimento das demandas energéticas, uma vez que, em níveis de produção mais elevados, a vaca mobiliza suas reservas corporais para mantença e produção. É também nessa fase inicial da lactação que a produção de leite atinge seu pico, tornando necessária atenção máxima à dieta fornecida.

O consumo de MS, além de determinar a quantidade de nutrientes disponíveis para mantença e produção de um animal (NRC, 2001), éimportante na formulação de dietas para evitar super ou subfornecimento de nutrientes, que poderiam causar efeitos adversos à saúde dos animais ou onerar os custos. Portanto, quando se refere ao sistema de produção de leite, deve-se considerar os custos com alimentação, o potencial genético dos animais e o ambiente no qual o animal está inserido. Os volumosos também têm efetiva participação na alimentação dos ruminantes.

Em comparação a outras forrageiras tropicais, a canade-açúcar conserva seu valor nutritivo por períodos relativamente prolongados, com aumento do conteúdo celular, em razão de seu maior teor de sacarose, o que compensa a redução na digestibilidade dos outros nutrientes e favorece o aumento da digestibilidade da MS em geral (Lima \& Mattos, 1993; Borges \& Pereira, 2003).

Preston \& Leng (1978), citados por Borges \& Pereira (2003), conduziram vários estudos com a utilização da cana-de-açúcar e apontaram o fornecimento ruminal de amido e proteína insatisfatório e, como principal causa do baixo consumo de MS, a baixa digestibilidade da fibra. Dietas à base de cana-de-açúcar possuem ainda grande quantidade de carboidratos solúveis e oferece condições favoráveis ao crescimento de protozoários, que, em alta população, prejudicam o crescimento de bactérias em virtude da maior predação, tornando necessária a adição de uma fonte de compostos nitrogenados não-protéicos (NNP), como a uréia, a fim de elevar o teor de PB e maximizar a produção bacteriana.

De acordo com Huber (1978), citado por Sucupira (1998), aproximadamente $80 \%$ das bactérias ruminais, particularmente as celulolíticas, utilizam melhor a amônia como forma de nitrogênio para a síntese de proteína microbiana e, portanto, é necessária disponibilidade adequada deste composto para que ocorra o crescimento desses microrganismos. Todavia, Stacchini (1998) relatou que a eficiência da síntese microbiana pode ser limitada em dietas com canade-açúcar e uréia pela ausência ou pequena disponibilidade de formas orgânicas de nitrogênio (proteína verdadeira).

Paiva et al. (1991), em pesquisa com vacas no terço inicial da lactação, verificaram que, mesmo com o uso de alto nível de uréia, no intuito de corrigir a deficiência de nitrogênio da cana-de-açúcar e utilizando-se uma fonte moderada de concentrado, esse volumoso, quando fornecido na forma exclusiva, não se mostrou como alimento adequado para vacas mestiças leiteiras com produção média de leite de $12 \mathrm{~kg} /$ dia.

Os farelos são bastante utilizados na suplementação de dietas à base cana-de-açúcar com uréia com a finalidade de fornecer amido e/ou proteína que escapariam à digestão microbiana do rúmen, sendo absorvidos como glicose e aminoácido no intestino delgado (Aroeira et al., 1993). De acordo com Faria (1993), os piores resultados obtidos com a cana-de-açúcar como alimento para os bovinos podem ser conseqüência de resultados obtidos em ensaios de alimentação em que o desbalanceamento das dietas provocou resultados muito desfavoráveis.

Objetivou-se neste trabalho avaliar o consumo, a digestibilidade total dos nutrientes da dieta e a produção e composição do leite em vacas no terço inicial da lactação alimentadas com dietas contendo teores crescentes de PB.

\section{Material e Métodos}

O experimento foi conduzido na fazenda Jaíta, em Macarani, BA, no período de maio a agosto de 2005. Foram utilizadas oito vacas leiteiras mestiças, lactantes, com peso médio de $400 \mathrm{~kg}$ e produção média de leite de $15,0 \mathrm{~kg}$ ao início do experimento, distribuídas em dois quadrados latinos (QL) balanceados $4 \times 4$, com média de 46 e 54 dias de lactação, respectivamente, ao início do experimento para os QL 1 e 2.

Os tratamentos foram compostos de quatro teores de PB na MS total da dieta: 11,5; 13,0; 14,5 e 16,0\%. A dieta foi balanceada para atender às exigências de energia preconizadas pelo NRC (2001). O concentrado (Tabela 1) foi composto de farelo de algodão e fubá de milho e fornecido na proporção de $40 \%$ da MS total da dieta. Como volumoso foi utilizada cana-de-açúcar, variedade RB 72454 suplementada com 1\% de uréia e sulfato de amônio (SA) na relação 9:1, com base na matéria natural, na proporção de 60\% da MS total da dieta.

A composição químico-bromatológica dos concentrados e da cana-de-açúcar é apresentada na Tabela 2 e das dietas experimentadas, na Tabela 3. 
Tabela 1 - Composição percentual dos ingredientes do concentrado

Table 1 - Composition of ingredients in the concentrates

\begin{tabular}{|c|c|c|c|c|}
\hline \multirow[t]{2}{*}{ Item } & \multicolumn{4}{|c|}{$\begin{array}{l}\text { Nível de PB na dieta (\%MS) } \\
\text { Level of } C P \text { in the diet }(\% D M)\end{array}$} \\
\hline & 11,5 & 13,0 & 14,5 & 16,0 \\
\hline $\begin{array}{l}\text { Fubá de milho } \\
\text { Corn meal }\end{array}$ & 89,31 & 77,34 & 65,61 & 54,01 \\
\hline $\begin{array}{l}\text { Farelo de algodão } \\
\text { Cottonseed meal }\end{array}$ & 6,33 & 18,28 & 30,17 & 42,06 \\
\hline $\begin{array}{l}\text { Calcário calcítico } \\
\text { Limestone }\end{array}$ & 0,79 & 0,92 & 0,98 & 1,08 \\
\hline $\begin{array}{l}\text { Fosfato bicálcico } \\
\text { Dicalcium phosphate }\end{array}$ & 1,66 & 1,56 & 1,36 & 1,00 \\
\hline $\begin{array}{l}\text { Sal } \\
\text { Salt }\end{array}$ & 0,37 & 0,35 & 0,33 & 0,31 \\
\hline $\begin{array}{l}\text { Flor de enxofre } \\
\text { Sulfur flower }\end{array}$ & 0,09 & 0,09 & 0,08 & 0,08 \\
\hline $\begin{array}{l}\text { Mistura mineral }{ }^{1} \\
\text { Mineral mix }\end{array}$ & 1,46 & 1,47 & 1,47 & 1,47 \\
\hline
\end{tabular}

O experimento foi constituído de quatro períodos experimentais de 15 dias, os sete primeiros para adaptação à dieta e os demais para coletas. Os animais foram mantidos em baias individuais, onde receberam o alimento na forma de mistura completa ad libitum, duas vezes ao dia, após as ordenhas da manhã e da tarde, de modo a permitir 5 a $10 \%$ de sobras na matéria natural. O peso dos animais foi calculado pela média dos pesos ao início e final de cada período experimental e os consumos diários foram determinados pela diferença entre a dieta total oferecida e as sobras, coletadas e pesadas duas vezes ao dia (manhã e tarde).

A cana-de-açúcar foi colhida e despalhada no campo a cada três dias, armazenada próximo ao estábulo e picada com pontas em máquina forrageira no momento do fornecimento. Semanalmente, amostras eram coletadas para determinação da MS e ajuste da relação volumoso:concentrado da dieta. A concentração média de açúcares solúveis ( ${ }^{\circ}$ BRIX) do material analisado foi de 19,0.

As amostras do alimento oferecido (cana-de-açúcar e concentrado) e das sobras foram coletadas do 8 o ao $15 \underline{0}$ dia, enquanto as de fezes foram feitas diretamente da ampola retal, duas vezes em cada período experimental, uma às $8 \mathrm{~h}$ do $9 \underline{0}$ dia e a outra às $15 \mathrm{~h}$ do 15 o dia, de acordo com Vagnoni et al. (1997). Essas amostras foram acondicionadas em sacos plásticos e armazenadas a $-20^{\circ} \mathrm{C}$.

Ao término do período de coleta, as amostras de alimentos, sobras e fezes foram descongeladas, pré-secas em estufa de ventilação forçada a $60^{\circ} \mathrm{C}$ durante 72 a 96 horas e, posteriormente, trituradas em moinho de facas com peneira de poros de $1 \mathrm{~mm}$. Logo após, foram feitas amostras
Tabela 2 - Composição nutricional dos concentrados e da canade-açúcar (\%MS)

Table 2 - Nutritional composition of the concentrates and of sugar cane (\%DM)

\begin{tabular}{|c|c|c|c|c|c|}
\hline \multirow[t]{2}{*}{ Item } & \multicolumn{3}{|c|}{$\begin{array}{c}\text { Nível de PB } \\
\text { na dieta (\%MS) } \\
\text { Level of } C P \text { in } \\
\text { the diet }(\% D M)\end{array}$} & \multicolumn{2}{|c|}{$\begin{array}{c}\text { Cana de açúcar } \\
\text { uréia SA (9:1 } \\
\text { Sugar cane } \\
\text { urea AS }(9: 1\end{array}$} \\
\hline & 11,5 & 13,0 & 14,5 & 16,0 & \\
\hline MS (DM) & 86,50 & 85,70 & 85,40 & 84,90 & 24,60 \\
\hline MO (OM) & 93,86 & 93,18 & 92,64 & 92,15 & 97,47 \\
\hline $\mathrm{PB}(C P)$ & 11,22 & 15,97 & 19,51 & 23,42 & 11,36 \\
\hline $\mathrm{EE}$ & 3,31 & 3,51 & 3,27 & 2,26 & 1,09 \\
\hline FDN (NDF) & 11,84 & 12,04 & 14,59 & 15,00 & 47,20 \\
\hline $\mathrm{FDN}_{\mathrm{CP}}\left(N D F_{A P}\right)$ & 11,04 & 11,11 & 13,39 & 13,88 & 46,24 \\
\hline FDA $(A D F)$ & 4,13 & 5,16 & 6,84 & 8,18 & 26,85 \\
\hline $\mathrm{PIDN}^{1}$ (NDIP) & 5,39 & 6,29 & 7,41 & 8,25 & 6,41 \\
\hline PIDA $^{2}$ (ADIP) & 2,29 & 3,57 & 7,96 & 10,63 & 4,35 \\
\hline $\mathrm{CNF}^{3}(\mathrm{NFC})$ & 65,94 & 58,46 & 51,16 & 45,19 & 36,75 \\
\hline $\mathrm{CT}^{3}(\mathrm{TC})$ & 77,78 & 70,50 & 65,75 & 60,19 & 83,95 \\
\hline Cinzas (Ash) & 6,14 & 6,82 & 7,36 & 7,85 & 2,53 \\
\hline Lignina (Lig) & 0,87 & 2,07 & 3,06 & 7,49 & 4,35 \\
\hline
\end{tabular}

${ }^{1}$ Proteína insolúvel em detergente neutro, em \% da PB (insoluble protein in neutral detergent, in \% of CP).

2 Proteína insolúvel em detergente ácido, em \% da PB (insoluble protein in acid detergent, in \% of $C P$ ).

${ }^{3}$ Carboidratos não-fibrosos (CNF); carboidratos totais (CT) (non fiber carbohydrates - NFC; total carbohydrates - TC.

Tabela 3 - Composição nutricional das dietas experimentais (\%MS)

Table 3 - Nutritional composition of the experimental diets (\%DM)

\begin{tabular}{|c|c|c|c|c|}
\hline \multirow[t]{2}{*}{ Item } & \multicolumn{4}{|c|}{$\begin{array}{l}\text { Nível de PB na dieta (\%MS) } \\
\text { Level of CP in the diet (\%DM) }\end{array}$} \\
\hline & 11,5 & 13,0 & 14,5 & 16,0 \\
\hline MS (DM) & 49,36 & 49,04 & 48,92 & 48,72 \\
\hline MO (OM) & 96,02 & 95,75 & 95,54 & 95,34 \\
\hline $\mathrm{PB}(C P)$ & 11,31 & 13,21 & 14,62 & 16,19 \\
\hline PDR (RDP) & 10,21 & 11,01 & 11,50 & 12,10 \\
\hline PNDR (RUP) & 1,10 & 2,20 & 3,12 & 4,09 \\
\hline $\mathrm{EE}$ & 1,97 & 2,05 & 1,96 & 1,55 \\
\hline FDN (NDF) & 33,06 & 33,14 & 34,16 & 34,32 \\
\hline $\mathrm{FDN}_{\mathrm{CP}}\left(N D F_{A P}\right)$ & 32,16 & 32,18 & 33,09 & 33,29 \\
\hline FDA $(A D F)$ & 17,76 & 18,17 & 18,85 & 19,38 \\
\hline $\mathrm{PIDN}^{1}$ (NDIP) & 6,01 & 6,37 & 6,81 & 7,15 \\
\hline $\mathrm{PIDA}^{2}$ (ADIP) & 3,53 & 4,04 & 5,79 & 6,86 \\
\hline $\mathrm{CNF}^{3}(N F C)$ & 48,43 & 45,44 & 42,52 & 40,13 \\
\hline $\mathrm{CT}^{3}(\mathrm{TC})$ & 81,48 & 78,57 & 76,67 & 74,45 \\
\hline Lignina (Lig) & 2,96 & 3,44 & 3,83 & 5,61 \\
\hline NDT (TDN) & 69,49 & 67,85 & 68,59 & 68,05 \\
\hline
\end{tabular}

${ }^{1}$ Proteína insolúvel em detergente neutro, em \% da PB (insoluble protein in neutral detergent, in \% of $C P$ ).

2 Proteína insolúvel em detergente ácido, em \% da PB (insoluble protein in acid detergent, in \% of $C P$ )

${ }^{3}$ Carboidratos não-fibrosos (CNF); carboidratos totais (CT) (non fiber carbohydrates - NFC; total carbohydrates - TC

compostas com base no peso seco das amostras, por animal, em cada período experimental e armazenadas para as análises bromatológicas, segundo procedimentos descritos por Silva \& Queiroz (2005). 
Para determinação dos coeficientes de digestibilidade total dos nutrientes, utilizou-se a fibra em detergente ácido indigestível (FDAi) como indicador interno, obtida após 144 horas de incubação ruminal dos alimentos, das sobras e fezes, utilizando-se sacos da Ankon ${ }^{\circledR}$ (filter bag F57) (Cochran et al., 1986). Após o período de incubação, os sacos foram retirados dos animais por meio da fístula ruminal e imediatamente lavados em água corrente até se apresentar totalmente límpida. Todos os sacos foram submetidos à fervura em detergente ácido durante 1 hora.

As análises de MS, cinzas e compostos nitrogenados (CN) totais nos alimentos, nas sobras e nas fezes foram realizadas conforme procedimentos descritos por Silva \& Queiroz (2005). Para as análises de EE, pesaram-se 1,5 g das amostras de cana, sobras e fezes e 2,0 g das amostras dos concentrados, as quais foram embrulhadas em guardanapos de papel-seda $(14,0 \mathrm{~cm} \times 14,0 \mathrm{~cm})$ em forma de cartuchos. As extremidades foram grampeadas e as amostras foram levadas a estufa de ventilação forçada a $55^{\circ} \mathrm{C}$ por 12 horas, onde foram mantidas em dessecador até atingir temperatura ambiente e posteriormente pesadas. Em média, dez cartuchos foram colocados em conexões extratoras fracionadas Soxlet e mantidos sob aquecimento por 5 horas para extração da gordura com éter de petróleo (para os concentrados) ou éter etílico (demais amostras), adicionando-se, aproximadamente, $30 \mathrm{~mL}$ de éter por cartucho, em balões redondos de fundo chato com capacidade para 500 mL. Após a extração, os cartuchos foram novamente levados à estufa de ventilação forçada a $55^{\circ} \mathrm{C}$, por 12 horas. O teor de gordura foi obtido pela diferença entre os pesos dos cartuchos antes e após a extração e depois foi corrigido para MS.

Foram feitas modificações da metodologia padrão, descrita por Silva \& Queiroz (2005), para a realização das análises de FDN e FDA, adotando-se metodologias empregadas por Bier (1982) e Pell \& Schofield (1993), para utilização da autoclave. Para isso, foi realizada a validação a fim de se compararem os resultados das análises realizadas em autoclave e em bloco digestor, no entanto, não foram encontradas diferenças entre os métodos analisados $(P=0,12)$, o que comprovou a eficácia do uso da autoclave por ser mais prático. Uma alíquota $(50 \mathrm{~mL})$ da solução de detergente neutro ou ácido, de acordo com a análise em andamento, foi adicionada a $0,5 \mathrm{~g}$ da amostra (alimentos, sobras e fezes). Para as análises de FDN com alto teor de amido, adotou-se metodologia de Silva \& Queiroz (2005), com adaptações, incubando-se 0,5 g da amostra em $8 \mathrm{mLde}$ uréia $8 \mathrm{M}$ à temperatura de 80 a $90^{\circ} \mathrm{C}$ por 5 minutos.
A porcentagem de carboidratos totais (CT) foi obtida pela equação: $100-(\% \mathrm{~PB}+\% \mathrm{EE}+\%$ cinzas $)$ e a porcentagem de CNF foi calculada como $100-\left(\% \mathrm{FDN}_{\mathrm{cp}}+\% \mathrm{~PB}+\% \mathrm{EE}+\right.$ \%cinzas) (Sniffen et al., 1992). Para o cálculo de NDT, utilizou-se a equação proposta pelo NRC (2001): NDT = PBd $+($ EEd $\times 2,25)+$ FDNd + CNFd, em que d representa o respectivo nutriente digestível.

Amostras de 3 g de cana-de-açúcar trituradas em moinho de facas com peneira de poros de $5 \mathrm{~mm}$ e pré-secas em estufa a $60^{\circ} \mathrm{C}$ e amostras de $5 \mathrm{~g}$ do fubá de milho e do farelo de algodão moídas a $2 \mathrm{~mm}$ foram colocadas em sacos de náilon ( $6 \times 10 \mathrm{~cm}$, com $56 \mu \mathrm{m}$ de porosidade) para determinação das degradabilidades ruminais da MS e PB. Foram utilizados dois animais machos fistulados no rúmen alimentados com o mesmo concentrado experimental. Consideraram-se nove tempos de incubação $(0,2,4,8,16,24,48,72$ e 96 horas) com dois sacos para cada tempo por animal. Antes e após a incubação, os sacos foram pesados para determinação de MS e análise do $\mathrm{N}$ total. As equações para estimar os parâmetros da degradabilidade foram ajustadas ao modelo não-linear pelo método iterativo de Gauss-Newton utilizando-se o Sistema de Análises Estatísticas e Genéticas - SAEG (UFV, 1999).

Os coeficientes a, b e Kd para determinação da degradabilidade potencial da MS e PB foram obtidos pela seguinte equação: degradação de MS ou PB = a + b (1-e-Kdt $)$, em que $\mathrm{a}$ = fração solúvel; $\mathrm{b}$ = fração insolúvel potencialmente degradável; e Kd = taxa de degradação da fração b no tempo t. A degradabilidade efetiva da PB foi calculada utilizando-se a equação PDR = a + b $\times[\mathrm{Kd} /(\mathrm{Kd}+\mathrm{Kp})]$ em que $\mathrm{Kp}=$ taxa de passagem (Ørskov \& Mcdonald, 1979) e o conteúdo de PNDR foi calculado como 100 PDR.

A taxa de passagem foi calculada de acordo com o NRC (2001) utilizando-se as equações: Kp cana-de-açúcar = $3,054+0,614 \times$ CMS e Kp concentrado $=2,904+1,375 \times$ CMS $-0,020 \times \%$ do concentrado na dieta, em que CMS é o consumo de MS expresso em \%PC.

A produção de leite foi avaliada do $8^{0}$ ao $15^{\circ}$ - dia de cada período experimental. Amostras de leite da $1 \underline{\underline{a}}$ e $2^{2}$ ordenhas do $11^{\text {o }}$ dia foram coletadas e formaram uma amostra composta por animal para determinação dos componentes do leite. As amostras compostas foram obtidas pela mistura proporcional à produção de leite da manhã e da tarde (Pereira et al., 2005). As análises qualitativas do leite foram realizadas no Laboratório de Fisiologia da Lactação da Escola Superior de Agricultura Luiz de Queiroz - Piracicaba/ SP. A produção de leite foi corrigida para 3,5\% de gordura 
(PLG), pela equação citada por Sklan etal.(1992): $\mathrm{PLG}=(0,432$ $+0,1625 \times \mathrm{G}) \times$ kg de leite, em que $\mathrm{G}=\%$ de gordura do leite.

A eficiência alimentar foi computada para cada vaca, dividindo-se a produção média de leite pela ingestão média de MS de cada período experimental (Valadares Filho et al., 2000). Do mesmo modo, procedeu-se ao cálculo da eficiência de utilização de N, dividindo-se o N-total médio do leite pela ingestão média de $\mathrm{N}$-total da dieta (Broderick, 2003).

Os resultados foram avaliados por meio de análises de variância e regressão, utilizando-se o Sistema de Análises Estatísticas e Genéticas - SAEG (UFV, 1999). Os critérios utilizados para escolha do modelo foram o coeficiente de determinação $\left(\mathrm{R}^{2}\right)$ e a significância observada por meio do teste F, a 5\% de significância.

\section{Resultados e Discussão}

Os teores de PDR e PNDR, expressos na MS, obtidos nas dietas com 11,$5 ; 13,0 ; 14,5$ e $16,0 \%$ de PB foram de 10,21 e 1,$10 ; 11,01$ e 2,$20 ; 11,50$ e 3,12; 12,10 e 4,09\%, respectivamente (Tabela 3 ). Os maiores teores de PB,
PDR e PNDR nas dietas contribuíram para o aumento do consumo de MS (Tabela 4). Quando expressos em porcentagem da PB, os consumos apresentaram efeito linear positivo, com valores de 87,26 e 9,41; 80,97 e 16,11; 76,22 e 20,68; 72,40 e 24,49\%, respectivamente, para as dietas com 11,$5 ; 13,0 ; 14,5$ e 16,0\% de PB, o que está relacionado aos crescentes níveis de farelo de algodão nas dietas. Assim, os aumentos observados para os consumos de MS e PB contribuíram para a elevação nos consumos de PDR e PNDR.

Os valores recomendados pelo NRC (2001) para vacas com produção média diária de 13 kg de leite, para PDR e PNDR, são de 9,66 e 2,62\%, respectivamente. No entanto, os valores obtidos para a dieta com 16,0\% de PB foram superiores, 12,09\% de PDR e 4,09\% de PNDR, indicando que as vacas produziram média de 13,3 kg de leite ao dia.

Segundo Broderick (2003), os fatores que influenciam a utilização da PB da dieta são complexos e relacionados ao suprimento sincronizado de CNF:PDR, para manter as necessidades dos microrganismos ruminais, e de PNDR, com a digestibilidade intestinal adequada, permitindo que os requerimentos das vacas sejam supridos. Neste estudo,

Tabela 4 - Consumos médios diários de MS, MO, PB, PDR, PNDR, EE, FDN, FDA, carboidratos não fibrosos (CNF), carboidratos totais (CT) e NDT obtidos nos diferentes níveis de PB na dieta (\% MS)

Table 4 - Average daily intakes of DM, OM, CP, RDP, RUP, EE, NDF, ADF, non fiber carbohydrates (NFC), total carbohydrates (TC) and TDN, in function of the CP levels in the diet (\%DM)

\begin{tabular}{|c|c|c|c|c|c|c|c|}
\hline \multirow[t]{2}{*}{ Item } & \multicolumn{4}{|c|}{$\begin{array}{l}\text { Nível de PB na dieta (\%MS) } \\
\text { Level of CP in the diet }(\% D M)\end{array}$} & \multirow[t]{2}{*}{$\mathrm{CV} \%$} & \multicolumn{2}{|c|}{$\begin{array}{l}\text { Valor de P } \\
P \text {-value }\end{array}$} \\
\hline & 11,5 & 13,0 & 14,5 & 16,0 & & $\begin{array}{l}\text { Linear } \\
\text { Linear }\end{array}$ & $\begin{array}{l}\text { Quadrático } \\
\text { Quadratic }\end{array}$ \\
\hline & \multicolumn{4}{|c|}{ Consumo (kg/d) (Intake) } & & & \\
\hline MS (DM) & 9,30 & 10,71 & 11,24 & 11,89 & 10,459 & $0,0016^{1}$ & n.s. \\
\hline PDR (RDP) & 0,95 & 1,18 & 1,29 & 1,44 & 9,851 & $0,0000^{4}$ & n.s. \\
\hline PNDR (RUP) & 0,10 & 0,23 & 0,35 & 0,49 & 8,524 & $0,0000^{5}$ & n.s. \\
\hline $\mathrm{EE}$ & 0,18 & 0,21 & 0,22 & 0,22 & 9,950 & n.s. & n.s. \\
\hline FDN (NDF) & 2,76 & 3,26 & 3,63 & 3,90 & 11,903 & $0,0002^{6}$ & n.s. \\
\hline FDA (ADF) & 1,52 & 1,83 & 1,99 & 2,20 & 11,159 & $0,0000^{7}$ & n.s. \\
\hline CNF (NFC) & 4,91 & 5,33 & 5,19 & 5,22 & 10,103 & n.s. & n.s. \\
\hline \multirow[t]{2}{*}{ FDN (NDF) } & 0,69 & 0,82 & 0,92 & 0,98 & 13,219 & $0,0000^{11}$ & n.s. \\
\hline & \multicolumn{4}{|c|}{ Consumo $\left(\mathrm{g} / \mathrm{kg}^{0,75}\right)$ (Intake, $\left.\mathrm{g} / \mathrm{kg}^{0.75}\right)$} & & & \\
\hline MS (DM) & 104,77 & 120,44 & 126,77 & 133,41 & 10,738 & $0,0001^{12}$ & n.s. \\
\hline
\end{tabular}

n.s.: não-significativo $(P>0,05)$ (not significant, $P>0.05)$.

${ }^{1} \hat{Y}=3,1975+0,5518 X\left(r^{2}=0,95\right) ;{ }^{2} \hat{Y}=3,2659+0,5124 X\left(r^{2}=0,94\right) ;{ }^{3} \hat{Y}=-1,1311+0,1954 X\left(r^{2}=0,99\right) ;{ }^{4} \hat{Y}=-0,2317+0,1052 X\left(r^{2}=0,99\right) ;{ }^{5} \hat{Y}=-0,8685$ $+0,0845 X\left(r^{2}=0,99\right) ;{ }^{6} \hat{Y}=-0,11890,2550 X\left(r^{2}=0,98\right) ;{ }^{7} \hat{Y}=-0,1270+0,1462 X\left(r^{2}=0,98\right) ;{ }^{8} \hat{Y}=4,3149+0,3077 X\left(r^{2}=0,89\right) ;{ }^{9} \hat{Y}=2,2370+0,3791 X$ $\left(r^{2}=0,96\right) ;{ }^{10} \hat{Y}=0,8328+0,1376 X\left(r^{2}=0,94\right) ;{ }^{11} \hat{Y}=-0,0362+0,0647 X\left(r^{2}=0,98\right) ;{ }^{12} \hat{Y}=36,7680+6,1512 X\left(r^{2}=0,94\right)$. 
não houve diferença para os consumos de EE e CNF entre as dietas, no entanto, o consumo de FDN apresentou variação linear positiva, relacionada ao aumento da fração insolúvel potencialmente degradável da FDN (76,33\%, em média) proveniente do farelo de algodão das dietas com maiores teores de PB (Valadares Filho et al., 2002). Mesmo com a redução dos teores de CT das dietas $(81,48 ; 78,57$; 76,67 e 74,45, respectivamente, para as dietas com 11,5; 13,0; 14,5 e 16,0\% de PB), o consumo desses carboidratos aumentou de acordo com os teores crescentes de PB, o que pode ser explicado pelo aumento da ingestão de FDN, e não pelos teores de CNF. O efeito linear crescente foi constatado também para os consumos de MO, PB e NDT.

Geralmente o consumo aumenta de acordo com a elevação do peso corporal (PC), portanto, é mais conveniente expressar o consumo em relação ao peso corporal do animal.

Entretanto, segundo Mertens (1994), a base para expressar o consumo em relação ao peso metabólico ou em porcentagem do peso corporal depende da limitação da ingestão, se foi decorrente de fator energético ou de enchimento, respectivamente.

Neste experimento, a digestibilidade total da MS (superior a $66 \%$ para todas as dietas experimentais) e a variação no teor de CNF de 48,43; 45,44; 42,52 e 40,13\% para as dietas com 11,5; 13,0; 14,5 e 16,0\% de PB, respectivamente, podem indicar que a limitação do consumo foi fisiológica, em virtude do fator energético. Além disso, o modelo "FDNconsumo de energia”, citado por Mertens (1994), prevê que a ingestão é limitada pelo enchimento do rúmen quando o consumo diário de FDN e maior que 11 a $13 \mathrm{~g} / \mathrm{kg}$ do PC. Nesse experimento, o consumo de FDN situou-se abaixo da capacidade ótima do consumo de fibra, pois variou de 6,9 a $9,8 \mathrm{~g} / \mathrm{kgPC}$.

Os resultados indicaram que os menores valores de consumo dos animais estão relacionados à baixa digestibilidade da fibra da cana-de-açúcar associada ao alto teor de carboidratos fermentáveis nas dietas. No entanto, o aumento dos teores de PB das dietas favoreceu o consumo, provavelmente em razão da melhor utilização da fibra proveniente da cana, o que explica as semelhanças nas respostas de consumo em $\mathrm{kg} / \mathrm{dia}$ \% $\% \mathrm{PC}$ e g $/ \mathrm{kg}^{0,75}$. Assim, o aumento dos consumos de MS com a elevação da PB das dietas parece não estar relacionado ao peso corporal e ao tamanho metabólico.

De acordo com Conrad et al. (1964), em dietas com digestibilidade da MS de 52 a 66\%, o consumo de MS está diretamente relacionado ao peso corporal, ao resíduo indigestível e à digestibilidade da MS e, em dietas com digestibilidade entre 67 e $80 \%$, ao peso metabólico, à produção e à digestibilidade. A baixa degradabilidade da cana no rúmen limita a taxa de passagem ruminal e, conseqüentemente, resulta em baixo consumo. Ørskov \& Hovell (1978) observaram que a taxa de digestão da fibra da cana-deaçúcar é muito baixa no rúmen e que o acúmulo de fibra não digestível limita o consumo voluntário.

Vilela et al. (2003), em pesquisa com vacas 5/8 HolandêsGir com média de produção de $8 \mathrm{~kg} /$ dia, testaram quatro dietas contendo $12,5 \%$ de $\mathrm{PB}$, compostas de diferentes suplementos para a cana-de-açúcar (uréia; uréia e farelo de algodão; uréia e milho grão moído; uréia e farelo de trigo) e obtiveram consumos de MS de 5,32; 7,85; 6,07 e 7,60 kg/ dia, respectivamente. Apesar do baixo consumo observado, associado à baixa degradabilidade da fibra no rúmen, os resultados comprovaram maior consumo de MS quando as dietas foram compostas exclusivamente de cana-de-açúcar como volumoso e suplementadas com farelo de algodão.

Pereira et al. (2000) verificaram que aproximadamente 72,48\% do conteúdo protéico do farelo de algodão apresentou degradação intermediária a lenta e, portanto, pode ser utilizado para proporcionar maior aporte de nitrogênio no intestino.

Apesar do aumento significativo nos consumos de MS, MO e FDN (Tabela 5), não foram observadas alterações nos coeficientes de digestibilidade desses nutrientes, que foram semelhantes $(\mathrm{P}>0,05)$ entre as dietas. A digestibilidade da PB não apresentou regressão significativa, mas o valor de $71,52 \%$ obtido para a dieta contendo $16,0 \%$ de PB foi numericamente superior ao de $64,74 \%$ observado para a dieta com $11,5 \%$ de PB.

Não houve efeito significativo $(\mathrm{P}>0,05)$ dos teores de PB das dietas sobre os coeficientes de digestibilidade dos CNF, provavelmente em virtude da elevada quantidade de carboidratos solúveis da cana-de-açúcar.

As dietas tiveram efeito linear positivo $(\mathrm{P}<0,05)$ sobre a produção do leite e de seus componentes (Tabela 6).

Entre os teores de 11,5 e $16,0 \%$ de PB na dieta, a produção de leite melhorou $26,41 \%$ ou $2,9 \mathrm{~kg} / \mathrm{dia}$. Para a produção de leite corrigida para 3,5\% de gordura, os acréscimos foram de $29,76 \%$ ou $3,05 \mathrm{~kg} /$ dia e as produções de gordura e proteína tiveram aumento de 110,75 e 95,89 g/dia, respectivamente, entre os teores de 11,5 e $16,0 \%$ de PB na dieta. O teor de 16,0\% de PB na dieta com cana-de-açúcar como volumoso exclusivo propiciou as melhores respostas de produção de leite corrigida ou não para 3,5\% de gordura.

Mayer et al. (1997), em pesquisa para avaliação de dietas contendo diferentes teores de PDR (70,0; 60,0; 52,0 e 45,0\% de degradabilidade da PB) em vacas mestiças na fase inicial da lactação com produção média de leite de 20 kg/dia, observaram que a produção não aumentou com 
Tabela 5 - Coeficientes de digestibilidade total de MS, MO, PB, EE, FDN, carboidratos não fibrosos (CNF) e carboidratos totais (CT) de dietas com diferentes níveis de PB (\%MS)

Table 5 - Coefficients of total apparent digestibility of DM, OM, CP, EE, NDF, non fiber carbohydrates (NFC) and total carbohydrates (TC), in function of the CP levels in the diet (\%DM)

\begin{tabular}{|c|c|c|c|c|c|c|c|}
\hline \multirow[t]{2}{*}{ Item } & \multicolumn{4}{|c|}{$\begin{array}{l}\text { Nível de PB na dieta (\%MS) } \\
\text { Level of } C P \text { in the diet }(\% D M)\end{array}$} & \multirow[t]{2}{*}{ CV \% } & \multicolumn{2}{|c|}{$\begin{array}{l}\text { Valor de } \mathrm{P} \\
P \text {-value }\end{array}$} \\
\hline & 11,5 & 13,0 & 14,5 & 16,0 & & $\begin{array}{l}\text { Linear } \\
\text { Linear }\end{array}$ & $\begin{array}{l}\text { Quadrático } \\
\text { Quadratic }\end{array}$ \\
\hline MS (DM) & 69,39 & 68,40 & 69,27 & 68,99 & 6,145 & n.s. & n.s. \\
\hline MO (OM) & 70,95 & 69,46 & 70,39 & 70,00 & 6,038 & n.s. & n.s. \\
\hline $\mathrm{PB}(C P)$ & 64,74 & 67,88 & 69,45 & 71,52 & 12,789 & n.s. & n.s. \\
\hline CNF (NFC) & 93,40 & 93,63 & 93,95 & 94,26 & 4,045 & n.s. & n.s. \\
\hline $\mathrm{CT}(T C)$ & 71,63 & 69,30 & 69,92 & 68,79 & 5,900 & n.s. & n.s. \\
\hline
\end{tabular}

n.s.: não-significativo $(P>0,05)$ (not significant, $P>0.05)$

Tabela 6 - Produção de leite corrigida para 3,5\% de gordura (LCG), produção de leite (PL), eficiência de utilização da MS (kg leite/kg MS consumida), eficiência de utilização de $\mathrm{N}$ ( $\mathrm{kg} \mathrm{N}$-leite/kg N-ingerido), teores e quantidades de gordura, PB, lactose, sólidos totais e N-uréia do leite (NUL) obtidas com dietas com diferentes níveis de PB (\%MS)

Table 6 - Production of FCM 3.5\%t or not (MP), efficiency of DM assimilation ( $\mathrm{kg}$ milk/kg DM intake), efficiency of nitrogen compounds ( $N$ ) assimilation ( $\mathrm{kg}$ $\mathrm{N}$-milk/kg N-intake), concentration and amount of milk fat (F), CP, lactose, total solids (TS) and milk urea nitrogen (MUN), in function of the CP levels in the $\operatorname{diet}(\% \mathrm{DM})$

\begin{tabular}{|c|c|c|c|c|c|c|c|}
\hline \multirow[t]{2}{*}{ Item } & \multicolumn{4}{|c|}{$\begin{array}{l}\text { Nível de PB na dieta (\%MS) } \\
\text { Level of } C P \text { in the diet }(\% D M)\end{array}$} & \multirow[t]{2}{*}{ CV \% } & \multicolumn{2}{|c|}{$\begin{array}{l}\text { Valor de P } \\
P \text {-value }\end{array}$} \\
\hline & 11,5 & 13,0 & 14,5 & 16,0 & & $\begin{array}{l}\text { Linear } \\
\text { Linear }\end{array}$ & $\begin{array}{l}\text { Quadrático } \\
\text { Quadratic }\end{array}$ \\
\hline LCG $(\mathrm{kg} / \mathrm{d})(M P F)$ & 10,25 & 12,20 & 12,09 & 13,30 & 12,810 & $0,0071^{1}$ & n.s. \\
\hline PL $(\mathrm{kg} / \mathrm{d})(M P)$ & 10,98 & 12,11 & 12,79 & 13,88 & 8,221 & $0,0049^{2}$ & n.s. \\
\hline Eficiência MS (DM efficiency) & 1,23 & 1,13 & 1,14 & 1,17 & 8,930 & n.s. & n.s. \\
\hline Gordura (g/d) (Fat) & 338,67 & 428,59 & 403,93 & 449,42 & 18,503 & $0,0364^{4}$ & n.s. \\
\hline PB (\%) (CP) & 2,9 & 3,0 & 3,0 & 3,0 & 3,126 & n.s. & n.s. \\
\hline $\mathrm{PB}(\mathrm{g} / \mathrm{d})(C P)$ & 320,85 & 357,95 & 384,85 & 416,74 & 9,410 & $0,0023^{5}$ & n.s. \\
\hline Lactose (\%) & 4,53 & 4,56 & 4,55 & 4,62 & 2,228 & n.s. & n.s. \\
\hline Lactose $(\mathrm{g} / \mathrm{d})$ & 499,52 & 553,23 & 582,30 & 639,30 & 9,108 & $0,0106^{6}$ & n.s. \\
\hline Sólidos totais (\%) (Total solids) & 11,55 & 12,22 & 11,74 & 11,97 & 5,186 & n.s. & n.s. \\
\hline
\end{tabular}

n.S.: não-significativo $(P>0,05)($ not significant, $P>0.05)$.

${ }^{1} \hat{Y}=3,6684+0,6028 X\left(r^{2}=0,85\right) ;{ }^{2} \hat{Y}=3,8578+0,6241 X\left(r^{2}=0,99\right) ;{ }^{3} \hat{Y}=0,4730-0,0191 X\left(r^{2}=0,89\right) ;{ }^{4} \hat{Y}=0,1232+0,0205 X\left(r^{2}=0,68\right) ;{ }^{5} \hat{Y}=0,0817$ $+0,0209 X\left(r^{2} 0,99\right) ;{ }^{6} \hat{Y}=0,1576+0,0299 X\left(r^{2}=0,99\right) ;{ }^{7} \hat{Y}=-3,5071+1,0591 X\left(r^{2}=0,99\right)$.

a utilização de concentrado de menor degradabilidade ruminal, portanto, ao atingirem o máximo potencial de produção, as vacas estariam desviando a quantidade de proteína ingerida para o ganho de peso em vez de aumentarem a produção de leite; para isso, as dietas deveriam ser oferecidas a animais com maior potencial genético.

Neste trabalho, a variação de peso dos animais alimentados com a mesma dieta foi negativa para as dietas contendo 11,$5 ; 13,0$ e 14,5\% de PB e positiva para a dieta com $16 \%$ de $\mathrm{PB}$, com valores de $-1,53 ;-0,20 ;-0,03$ e $0,50 \mathrm{~kg}$, respectivamente.

Segundo Lucci (1997), citado por Silva et al. (2001), a composição nitrogenada da dieta pode influenciar a taxa de gordura láctea, percentualmente, de modo que aumentos na concentração protéica de $12-14 \%$ para $18 \%$ podem reduzir a porcentagem de gordura em até $0,5 \%$, em virtude do aumento da produção de leite, enquanto os teores de proteína sofrem pequenos acréscimos com o aumento dos níveis de proteína dietética.

Entre proteína e gordura, a gordura é mais fortemente influenciada pela nutrição. Em casos extremos, o teor de proteína varia em torno de $0,4 \%$, enquanto a gordura pode variar de 2 a 3\%. Assim como a proteína, o teor da lactose do leite dificilmente é alterado (Carvalho, 2000). Os valores observados para o percentual de lactose do leite nas dietas experimentais foram semelhantes aos relatados por Carvalho 
(2000), com média de 4,57\%, e não diferiram ( $\mathrm{P}>0,05$ ) entre as dietas, assim como os valores percentuais de $\mathrm{PB}$, que não sofreram aumento linear com os acréscimos nos teores de PB das dietas (2,9; 3,0; 3,0 e 3,0\% para as dietas com 11,5; 13,0; 14,5 e 16,0\% de PB, respectivamente).

Os teores crescentes de PB na dieta não afetaram os teores percentuais de gordura e proteína do leite. O aumento na produção de leite pode estar associado ao crescente consumo da MS promovido pelos níveis de farelo de algodão nas dietas, uma vez que esse alimento também oferece maior aporte intestinal de proteína nãodegradável no rúmen (PNDR).

Cunninghan et al. (1996) concluíram que dietas contendo maiores quantidades de PB e PNDR melhoram a produção e a composição do leite, como conseqüência dos altos fluxos de $\mathrm{N}$ e aminoácidos essenciais para o intestino. Nesta pesquisa, a eficiência de $\mathrm{N}$ foi significativa $(\mathrm{P}<0,05)$, com variação decrescente, à medida que aumentaram os teores de PB da dieta, resultado semelhante ao observado por Pereira et al.(2005). No entanto, exceto para a dieta contendo $11,5 \%$ de PB, os teores de NUL mantiveram-se dentro dos parâmetros estabelecidos por Jonker et al.(1999), que relataram que a concentração de NUL deve variar de 10 a $16 \mathrm{mg} / \mathrm{dL}$ dependendo do nível de produção, pois valores superiores podem indicar excesso no consumo de $\mathrm{N}$ ou de proteína degradável no rúmen. Assim, a menor eficiência de utilização de N pode estar associada ao perfil de aminoácidos requeridos para a lactação, pois, a partir do momento que não satisfazem as exigências para produção do leite, os aminoácidos fornecidos pela dieta e/ou pelos microrganismos ruminais são utilizados em outras rotas metabólicas.

Neste estudo, vários fatores relacionados à eficiência de utilização de nutrientes para a produção de leite e ganho de peso foram favoráveis quando a PB dietética aumentou com a substituição do fubá de milho pelo farelo de algodão na suplementação da cana-de-açúcar, incluindo a utilização de MS, FDN e NDT da dieta.

\section{Conclusões}

Os consumos médios diários dos nutrientes foram significativamente maiores para a dieta com $16,0 \%$ de PB, uma vez que os maiores níveis de farelo de algodão promoveram maior aporte de PDR e PNDR e foram suficientes para manter as necessidades dos microrganismos ruminais e promover a utilização adequada da proteína no intestino, permitindo que os requerimentos das vacas fossem supridos.

Os crescentes teores de proteína na dieta não influenciaram a porcentagem de proteína, gordura e lactose do leite, mas favoreceram a produção de leite, que foi maior nos animais alimentados com a dieta com $16,0 \%$ de PB.

\section{Agradecimento}

À COOPARDO - Cooperativa Mista do Médio Rio Pardo, pelo apoio financeiro, à Fazenda Jaíta, especialmente ao Dr. Paulo Lacerda, pela cessão dos animais e das instalações, e ao setor de transportes da UESB, pela contribuição à realização deste estudo.

\section{Literatura Citada}

BIER, O. Bacteriologia e imunologia. 22.ed. São Paulo: Melhoramentos, 1982. 1062p.

BORGES, A.L.C.C.; PEREIRA, L.G.R. Cana-de-açúcar como volumoso para bovinos. In: MARQUES, D.C. (Ed.) Criação de bovinos. 7.ed. Belo Horizonte: Consultoria Veterinária e Publicações, 2003. p.221-224.

BRODERICK, G.A. Effects of varying dietary protein and energy levels on the production of lactating dairy cows. Journal of Dairy Science, v.86, n.4, p.1370-1381, 2003.

CARVALHO, M.P. Manipulação da composição do leite por meio de balanceamento de dietas de vacas leiteiras. In: FONSECA, L.F.L.; SANTOS, M.V. (Eds.) Qualidade do leite e controle de mastite. São Paulo: Lemos, 2000. p.163-169.

COCHRAN, R.C.; ADAMS, D.C.; WALLACE, J.D. et al. Predicting digestibility of different diets with internal markers: evaluation of four potential markers. Journal of Animal Science, v.63, p.1476-1483, 1986.

CONRAD, H.R.; PRATT, A.D.; HIBBS, J.W. Regulation of feed intake in dairy cows. 1. Change in importance of physical and physiological factors with increasing digestibility. Journal of Dairy Science, v.47, n.1, p.54-62, 1964.

CUNNINGHAM, K.D.; CECAVA, M.J.; JOHNSON, T.R. et al. Influence of source and amount of dietary protein on milk yield by cows in early lactacion. Journal of Dairy Science, v.79, n.4, p.620-630, 1996.

FARIA, V.P. O uso da cana-de-açúcar para bovinos no Brasil. In: SIMPÓSIO SOBRE NUTRIÇÃO DE BOVINOS, 5., 1993, Piracicaba. Anais... Piracicaba: Fundação de Estudos Agrários Luiz de Queiroz, 1993. p.1-16.

JONKER, J.S.; KOHN, R.A.; ERDMAN, R.A. Milk urea nitrogen target concentrations for lactating dairy cows fed according to national research council recommendations. Journal of Dairy Science, v.82, n.6, p.1261-1273, 1999.

MAYER, L.R.R.; SILVA, J.F.C.; VALADARES FILHO, S.C. et al. Rações com diferentes teores de proteína degradada no rúmen para vacas em lactação. 1. Consumo, produção e composição do leite. Revista Brasileira de Zootecnia, v.26, n.4, p.813-823, 1997.

MERTENS, D.R. Regulation of forage intake. In: FAHEY, Jr. (Ed.). Forage quality, evaluation and utilization. Madison: American Society of Agronomy, 1994. p.450-493.

NATIONAL RESEARCH COUNCIL - NRC. Nutrient requirements of dairy cattle. 7.ed.rev. Washington, D.C.: National Academic Press, 2001. 381p.

ØRSKOV, E.R.; HOVELL, F.D. Digestion ruminal del heno (medida através de bolsas de dracon) en el ganado alimentado com caña de azucar o heno de pangola. Tropical Animal Production, v.3, n.1, p.9-11, 1978.

ØRSKOV, E.R.; McDONALD, I. The estimation of protein degradabilility in the rumen from incubation measurements weighted according to rate of passage. Journal of Agricultural Science, v.92, n.2, p.499-503, 1979. 
PAIVA, J.A.J.; MOREIRA, H.A.; CRUZ, G.M. et al. Cana-de-açúcar associada à uréia/sulfato de amônio como volumoso exclusivo para vacas em lactação. Revista Brasileira de Zootecnia, v.20, n.1, p.91-99, 1991.

PELL, A.N.; SCHOFIELD, P. Computerized monitoring of gas production to measure forage digestion in vitro. Journal of Dairy Science, v.76, n.4, p.1063-1073, 1993.

PEREIRA, E.S.; QUEIROZ, A.C.; PAULINO, M.F. et al. Determinação das frações protéicas e de carboidratos e taxas de degradação in vitro da cana-de-açúcar, da cama de frango e do farelo de algodão. Revista Brasileira de Zootecnia, v.29, n.6, p.1887-1893, 2000.

PEREIRA, M.L.A.; VALADARES FILHO, S.C.; VALADARES, R.F.D. et al. Consumo, digestibilidade aparente total, produção e composição do leite em vacas no terço inicial da lactação alimentadas com níveis crescentes de proteína bruta no concentrado. Revista Brasileira de Zootecnia, v.34, n.3, p.1029-1039, 2005.

SILVA, D.J.; QUEIROZ, A.C. Análise de alimentos: métodos químicos e biológicos. 3.ed. Viçosa, MG: Editora UFV, 2005. $235 p$.

SILVA, R.M.N.; VALADARES, R.F.D.; VALADARES FILHO, S. de C. et al. Uréia para vacas em lactação 1.consumo, digestibilidade, produção e composição do leite. Revista Brasileira de Zootecnia, v.30, n.5, p.1639-1649, 2001.

SKLAN, D.; ASHKENNAZI, R.; BRAUN, A. et al. Fatty acids, calcium soaps of fatty acids, and cottonseeds fed to high yielding cows. Journal of Dairy Science, v.75, n.9, p.2463-2472, 1992.

SNIFFEN, C.J.; O'CONNOR, J.D.; van SOEST, P.J. et al. A net carbohydrate and protein system for evaluating cattle diets: II. Carbohydrate and protein availability. Journal of Animal Science, v.70, n.11, p.3562-3577, 1992.

STACCHINI, P.F. Efeito dos teores de uréia e do farelo de soja sobre a digestibilidade e balanço de nitrogênio em vacas leiteiras alimentadas com cana-de-açúcar. Piracicaba:
Escola Superior de Agricultura Luiz de Queiroz, 1998. 67p. Dissertação (Mestrado em Agronomia) - Escola Superior de Agricultura Luiz de Queiroz, 1998.

SUCUPIRA, M.C.A. Efeito de níveis crescentes de uréia no consumo, volume ruminal e taxa de passagem em vacas holandesas alimentadas com cana-de-açúcar. Piracicaba: Escola Superior de Agricultura Luiz de Queiroz, 1998. 66p. Dissertação (Mestrado em Agronomia) - Escola Superior de Agricultura Luiz de Queiroz, 1998.

UNIVERSIDADE FEDERAL DE VIÇOSA - UFV. Sistema de análises estatísticas e genéticas - SAEG. Viçosa, MG: 1999. 97p.(Apostila).

VAGNONI, D.B.; BRODERICK, G.A.; CLAYTON, M.K. et al. Excretion of purine derivatives by holstein cows abomasally infused with incremental amounts of purines. Journal of Dairy Science, v.80, p.1695-1702, 1997.

VALADARES FILHO, S.C.; BRODERICK, G.A.; VALADARES, R.F.D. et al. Effect of replacing alfafa silage with high moisture corn on nutrient utilization and milk production. Journal of Dairy Science, v.83, n.1, p.106-114, 2000.

VALADARES FILHO, S.C.; ROCHA JR., V.R.; CAPPELLE, E.R. Tabelas brasileiras de composição de alimentos para bovinos. Viçosa, MG: Universidade Federal de Viçosa, 2002. $297 \mathrm{p}$.

VILELA, M.S.; FERREIRA, M.A.; VÉRAS, A.S.C. et al. Avaliação de diferentes suplementos para vacas mestiças em lactação alimentadas com cana-de-açúcar: desempenho e digestibilidade. Revista Brasileira de Zootecnia, v.32, n.3, p.768-777, 2003. 